\title{
EMPLOYEE RETENTION STRATEGIES - IN INDIAN INFORMATION TECHNOLOGY SECTOR
}

\author{
Manju Dhillon \\ Assistant Professor, Department of Business Administration, Maharaja Surajmal Institute, \\ IP University, Delhi, India.
}

\begin{abstract}
Employee turnover is biggest challenge for every organization. Even though all types of the organizations are technology driven, yet human resources are required to run the technology. With all round development in each and every area of the economy, there is stiff competition in the market. With this development and competition, there are lots and lots of avenues and opportunities available in the hands of the human resources. Nowadays the biggest challenge of organizations is not only managing its employees but also retaining its talented employees. Indian IT sector; which is one of major contributors to the economy is also affected by the problem of employee retention. In order to address the issue of employee retention, companies adopt some retention strategies. In this paper, we will find out the retention strategies being followed in Indian IT sector. Primary data is collected from five IT companies i.e. Wipro, Infosys, HCL, Accenture and TCS, of Indian IT sector. The suitable statistical tools are used to draw the conclusion. The study can serve a great deal for HR departments of Indian IT sector in order to reduce attrition.
\end{abstract}

Key words: Employee turnover, HR problems, Retention strategies and Indian IT sector

Cite this Article: Manju Dhillon, Employee Retention Strategies- In Indian Information Technology Sector, International Journal of Management, 11(12), 2020, pp 1621-1629.

http://iaeme.com/Home/issue/IJM?Volume=11\&Issue=12

\section{INTRODUCTION}

Employee turnover is defined as the ratio of the number of workers replaced in a given time period to the average number of workers. Wood (1992) defines turnover as a replacement cycle, in which a new employee has to be hired and trained against a vacancy, either voluntarily or involuntarily. Price (1977) defines turnover as the ratio of the number of organizational members who have left during the period being considered which is divided by the average number of people in that organization during the period. Bliss (2004) argues that 
cost associated with employee turnover can be: recruitment costs, training costs, lost productivity costs, new hire costs, and lost sales costs. Each employee walking out of the door cost the company under different heads such as; training, education, licensing and experience lost. The cost is doubled with replacement hiring as the same costs occur with the new recruit. The cost of advertising, moving, and hiring is approximated to one third of annual salary of hired employee. The time is another cost that company has to bear in addition to the money. Time of HR and other department heads is wasted in hiring which otherwise could have been utilized for more productive purposes. Further the time gap between an employee leaving and another employee joining costs the company a significant amount of work of that duration. Team dynamics is another major problem caused by uncontrolled attrition. It is very difficult to infuse a new member and build a new team every now and then for the project. The understanding of a team gets shattered by attrition. The changing team dynamics leave a negative effect on overall productivity of the team and company. Since the new employee takes time to match the pace of the team and he/she may not delivery the desired output in terms of time or quality immediately. The momentum of team output gets a significant hit by attrition. Losing on the continuity of the business is yet another cost that a company has to bear. A client may be dealt by an employee of the company and the client has a good relationship and confidence in the particular employee, when the employees change frequently the client loses its confidence in the company in such cases.

As discussed above, the employee turnover affects the overall performance of the company from several directions. Therefore the companies do not want to let employee turnover rate go beyond control and try to implement several retention strategies. The major retention strategies are management support, training and development programmes, rewards and recognition, attractive fringe benefits, workers participation in management activities, onsite opportunities and flexible working hours. Though companies take several steps towards these four important issues impacting retention, it is very important to understand the employees' perspective on these strategies.

In this paper, an attempt is made to look in to employees' perspective on these retention strategies with respect to five major IT companies, i.e., TCS, Accenture, Wipro, HCL and Infosys.

\section{LITERATURE REVIEW}

A number of authors have worked on retention strategies and their impact on reducing rate of attrition such as, (Ross and Zander, 1957) concluded that if personal needs of the employees are satisfied then there are more chances that the employees will not leave the organization. The study also suggests that there is less relation between the salary and satisfaction. Employer's job is to identify the needs of Individuals and fulfil them that can benefit both the organization and the employee as a whole. Mobley, et, al, 1979) suggest to understand the psychology of the employees and try to eliminate the variable that causes attrition. The study suggests to look into the retention strategies that can lead to satisfaction in present and the strategies that can attract the personnel in the future. There are consequences of employee turnover some are positive and some are negative, the negative consequences are role centrality, cohesiveness of work group, tightness of labor market and levels in organizational hierarchy and the positive consequences are internal growth of the organization, career orientation and role performance curve (Barry, 1980). The study also recommends to evaluate each alternative carefully and then implement according to the situation. (Muchinsky and Murrow, 1980) stated that turnover must be viewed as a dynamic process involving socio, economical and psychological factors. Employers must find out the factors under these three heads to understand the process of attrition. The study also recommends that the employee 
seeking voluntary retirement might be leaving because of existing opportunities. So, this becomes a determinant for the other employees. (Michaels and Spector, 1982) analyzed two variables organizational commitment and confirmed pre-employment expectancies. The study says that it has a positive impact on the organizational commitment other than that consideration by superior led to maximum satisfaction amongst the employees. Factors like salary, tenure and organizational level has no relation with the above model. Mowday (1984) explains that the managers should study rigoursly to know the reason why employees left the organization and try to eliminate the variables that results in employee turnover and managers should have a clear idea which strategy is best and the right time to implement it. The study also says that it will become a necessity rather than choice if the attrition rate is likely to be high in the future. It has become a challenge for the managers to retain the employees after the introduction of computers as supply of skilled labor is less and demand is more. Employees switch between companies and use it as a tool for career advancement.(Carstenand Specter,1987) proposes that there is weak relationship between satisfaction and turnover at the time of high unemployment and vice versa. In other words, the study says that even people are dissatisfied with their current job they don't think of switching as there are less alternatives and if there are more alternatives and employees are not satisfied, they plan to move from one company to another. (Campion, 1991) analyses three aspects of organizational consequences named functionality, availability and utility. This study measures the turnover Intentions of employees in the organizations It has also says that the companies are deficient in Information as they usually takes one factor for the turnover. (Sheridan, 1992) finds that organizations that value inter-personal relationships are more likely to retain employees for longer duration as compared to companies that value work based values. There was a significant difference of 14 months duration in both the organizations. The study also says that the companies cannot skip on the replacement cost but they can delay the cost of replacement cost by increasing the survival period of employees in the organization. Different kind of people are suitable for different kinds of organizations and if the policies, functioning and culture doesn't suit them they soon leave the organization. So the employer's job is to find the right fit employees for the organization so they can manage to reduce heavy cost and time of recruiting at short intervals. Managers must find employees that fit to the organization culture. (Hall, 1993) finds that there are six Intangible resources named culture, networks, data bases, reputation, employee Know-how that have implications on the management. These six intangible resources ensures the success of the organization as it makes employees feel that the organization cares for them and feeling of belongingness compels them to work with more efficiency and thereby earning profits. However, manager's job is to identify which factors influence the employees the most and try to make it feasible for everyone working there. (Despres and Hiltrop, 1995) proposed that managers should not focus only on financial Incentives but should emphasize on finding ways to encourage intrinsic factors that leads to motivation. Knowledge has become a key factor for successful functioning of any organization. Employers need to find ways to retain these kinds of workforce for the smooth functioning. Compensation and reward systems can play a significant role in achieving the same. Further (Fey, Bjorkman, and Pavlovskaya, 2000) provides with different variables for retention of managerial and non-managerial employees. Job security, performance are the most significant variables in retaining the talent and at the non-managerial level and promotions on merit and firm's performance are the key factors at the managerial level. Apart from these there are several other factors as well that contributes in reducing employee turnover such as high salaries, technical sessions etc. (Kim, 2005) stated that it is very important to retain talented and competent employees in the organization to achieve goals with efficiency. The study proposes variables such as work exhaustion, participation in management, opportunities for growth and advancement have significant impact on the 
employee's intention to stay. Salary does not have a significant Impact on the retention. The research on retention strategies and the impact of these strategies can be observed in Ghosh (2011 and 2015) different retention strategies are followed at different organizations.

\section{OBJECTIVES OF THE STUDY}

There is significant variation in retention strategies from company to company

\section{RESEARCH METHODOLOGY}

As discussed above the objective of the paper is to identify and study the employee retention strategies in Indian IT sector. A questionnaire is developed on the basis of Literature review, in total 15 statements were included in the questionnaire along with necessary demographics.

These statements are given by;

\begin{tabular}{|c|l|}
\hline D.1 & Management support for higher education is available. \\
\hline D.2 & Training and Development programs are provided. \\
\hline D.3 & Rewards and Recognition given to deserving employees. \\
\hline D.4 & Attractive fringe benefits are provided. \\
\hline D.5 & Workers participation in management activities. \\
\hline D.6 & Onsite opportunities are provided. \\
\hline D.7 & Mentoring and Coaching sessions are given to employees. \\
\hline D. 8 & Flexible work timing is available. \\
\hline D.9 & Availability of day-care facility. \\
\hline D.10 & Promotion opportunities are provided. \\
\hline D.11 & Good welfare measures are taken. \\
\hline D.12 & Pleasant working environment is ensured. \\
\hline D.13 & New assignments and job rotations are available. \\
\hline D.14 & Career development opportunities are available. \\
\hline D.15 & Location transfer with promotion is given. \\
\hline
\end{tabular}

The statements are measured through a well-defined five point Likert scale of agreement. In total 660 responses are collected, after pilot testing 50 questionnaires. The frequency distribution of sample with respect to companies is as following;

Table 1 Distribution of Companies

\begin{tabular}{|l|l|c|c|c|c|}
\hline \multirow{5}{*}{ Valid } & Company & Frequency & Percent & Valid Percent & $\begin{array}{c}\text { Cumulative } \\
\text { Percent }\end{array}$ \\
\cline { 2 - 6 } & TCS & 232 & 35.2 & 35.2 & 35.2 \\
\cline { 2 - 6 } & Wipro & 134 & 20.3 & 20.3 & 55.5 \\
\cline { 2 - 6 } & Infosys & 121 & 18.3 & 18.3 & 73.8 \\
\cline { 2 - 6 } & Accenture & 114 & 17.3 & 17.3 & 91.1 \\
\cline { 2 - 6 } & HCL & 59 & 8.9 & 8.9 & 100.0 \\
\cline { 2 - 6 } & Total & 660 & 100.0 & 100.0 & 100.0 \\
\hline
\end{tabular}

Table 2 Overall Reliability Statistics of Retention Strategies

\begin{tabular}{|c|l|c|c|}
\hline Variables & Description & Number of items & Cronbach's $\boldsymbol{\alpha}$ \\
\hline D & Retention Strategies & 15 & 0.851 \\
\hline
\end{tabular}

The sample distribution is aligned with the employee strength of the Company. As mentioned, the questionnaire is filled by 660 employees. The testing has shown a good reliability of the instrument i.e. 0.851 and a good internal validity as the inter-item correlation remained high amongst the statements. Following tables present the result. 
Table 3 Reliability Statistics for Variables

\begin{tabular}{|c|l|c|c|}
\hline Variable & \multicolumn{1}{|c|}{ Description } & Number of Items & $\begin{array}{c}\text { Cronbach's Alpha } \\
\text { if Item Deleted }\end{array}$ \\
\hline D.1 & $\begin{array}{l}\text { Management support for higher education is } \\
\text { available. }\end{array}$ & 1 & 0.829 \\
\hline D.2 & Training and Development programs are provided. & 1 & 0.841 \\
\hline D.3 & $\begin{array}{l}\text { Rewards and Recognition given to deserving } \\
\text { employees }\end{array}$ & 1 & 0.842 \\
\hline D.4 & Attractive fringe benefits are provided. & 1 & 0.844 \\
\hline D.5 & Workers participation in management activities & 1 & 0.846 \\
\hline D.6 & Onsite opportunities are provided. & 1 & 0.844 \\
\hline D.7 & $\begin{array}{l}\text { Mentoring and Coaching sessions are given to } \\
\text { employees }\end{array}$ & 1 & 0.843 \\
\hline D.8 & Flexible work timing is available & 1 & 0.844 \\
\hline D.9 & Availability of day-care facility & 1 & 0.844 \\
\hline D.10 & Promotion opportunities are provided & 1 & 0.842 \\
\hline D.11 & Good welfare measures are taken & 1 & 0.845 \\
\hline D.12 & Pleasant working environment is ensured & 1 & 0.841 \\
\hline D.13 & New assignments and job rotations are available & 1 & 0.846 \\
\hline D.14 & Career development opportunities are available. & 1 & 0.842 \\
\hline D.15 & Location transfer with promotion is given. & & 0.842 \\
\hline
\end{tabular}

Table 4 Inter-Item Correlation Matrix for Retention Strategies

\begin{tabular}{|l|c|c|c|c|c|c|c|c|c|c|c|c|c|c|c|}
\hline & D.1 & D.2 & D.3 & D.4 & D.5 & D.6 & D.7 & D.8 & D.9 & D.10 & D.11 & D.12 & D.13 & D.14 & D.15 \\
\hline D.1 & 1.000 & & & & & & & & & & & & & & \\
\hline D.2 & .368 & 1.000 & & & & & & & & & & & & & \\
\hline D.3 & .394 & .273 & 1.000 & & & & & & & & & & & & \\
\hline D.4 & .377 & .247 & .288 & 1.000 & & & & & & & & & & & \\
\hline D.5 & .344 & .273 & .246 & .211 & 1.000 & & & & & & & & & & \\
\hline D.6 & .358 & .265 & .248 & .207 & .240 & 1.000 & & & & & & & & & \\
\hline D.7 & .366 & .277 & .255 & .275 & .197 & .268 & 1.000 & & & & & & & & \\
\hline D.8 & .369 & .316 & .196 & .297 & .220 & .298 & .288 & 1.000 & & & & & & & \\
\hline D.9 & .365 & .242 & .359 & .237 & .208 & .303 & .239 & .228 & 1.000 & & & & & & \\
\hline D.10 & .403 & .393 & .268 & .294 & .297 & .213 & .284 & .232 & .201 & 1.000 & & & & & \\
\hline D.11 & .359 & .280 & .170 & .235 & .222 & .219 & .302 & .223 & .258 & .267 & 1.000 & & & & \\
\hline D.12 & .436 & .317 & .307 & .300 & .197 & .303 & .318 & .223 & .327 & .222 & .271 & 1.000 & & & \\
\hline D.13 & .342 & .245 & .239 & .113 & .238 & .224 & .235 & .242 & .241 & .230 & .213 & .230 & 1.000 & & \\
\hline D.14 & .424 & .304 & .306 & .304 & .275 & .304 & .256 & .274 & .210 & .246 & .210 & .261 & .241 & 1.000 & \\
\hline D.15 & .413 & .252 & .316 & .268 & .205 & .251 & .238 & .242 & .223 & .326 & .251 & .259 & .289 & .308 & 1.000 \\
\hline
\end{tabular}

The positive correlations among the items clearly indicate the inter-item reliability and we can be assured that the items are measuring the related construct. After testing the reliability and validity of the data, the data is coded in SPSS 20.0 for analysis. Following alternate hypotheses related to objective is constructed and tested in the paper;

Ha: There is significant variation in retention strategies from company to company

\section{RESULT AND DISCUSSION}

In this section the data analysis is presented. Two important statistical measures are used for analysis here. First the comparison of mean scores is analyzed with respect to each statement so that level of agreement for each statement can be compared. Later the statistical 
significance of the different levels of agreement is analyzed using analysis of variance. First the means are compared for overall retention strategies and the analysis is presented.

There are five companies under study TCS, Accenture, Infosys, Wipro and HCL. The average of turnover intentions of employees working with these companies (Table 5). From table above it can be observed that in TCS the highest agreement appeared on the statements, "Rewards and Recognition given to deserving employees", this could be the prime strategy for TCS, it is also observed during the study that reward and recognition are major components in employee retention. On the other hand Wipro focuses most on, "Location transfer with promotion is given", this clearly shows that Wipro works on change of environment more rather than any other component. This may be due to the fact that stagnancy of work in IT sectors is debated over the period of time and change of environment and location may provide an employee breathe of freshness. In Infosys highest focus is on providing onsite opportunities and hence the highest agreement appeared on the statement, "Onsite opportunities are provided". This retention strategy can only work with the industry if it has enough options overseas. There is a charm amongst employees in working onsite and hence the retention strategies revolve around this in Infosys. Further in Accenture the highest agreement is observed on, "Good welfare measures are taken". It seems that the Accenture believed in providing welfare to employees and their Families. There are many companies that succeeded in high employee retention by focusing on employee welfare. This strategy provides employees a stress free environment and through this

Table 5 Statistical distribution of retention strategies

\begin{tabular}{|c|c|c|c|c|c|c|c|c|c|c|c|c|c|c|c|c|}
\hline \multicolumn{2}{|c|}{ Company } & D.1 & D.2 & D.3 & D.4 & D.5 & D.6 & D.7 & D.8 & D.9 & D.10 & D.11 & D.12 & D.13 & D.14 & D.15 \\
\hline \multirow{3}{*}{ TCS } & Mean & 2.88 & 2.91 & 3.04 & 2.93 & 2.93 & 2.88 & 2.96 & 3.01 & 3.00 & 2.83 & 2.86 & 2.95 & 2.97 & 2.95 & 2.94 \\
\hline & $\mathrm{N}$ & 232 & 232 & 232 & 232 & 232 & 232 & 232 & 232 & 232 & 232 & 232 & 232 & 232 & 232 & 232 \\
\hline & \begin{tabular}{|l|} 
Std. \\
Deviation
\end{tabular} & 1.405 & 1.046 & 1.029 & 1.042 & 1.015 & 1.038 & .993 & 1.002 & 1.036 & 1.047 & 988 & .999 & .982 & 995 & 1.075 \\
\hline \multirow{3}{*}{ Wipro } & Mean & 2.87 & 3.00 & 2.99 & 2.93 & 2.96 & 3.04 & 3.06 & 2.88 & 2.95 & 2.88 & 2.84 & 3.04 & 2.88 & 2.79 & 3.07 \\
\hline & $\mathrm{N}$ & 134 & 134 & 134 & 134 & 134 & 134 & 134 & 134 & 134 & 134 & 134 & 134 & 134 & 134 & 134 \\
\hline & \begin{tabular}{|l|} 
Std. \\
Deviation
\end{tabular} & 1.392 & 931 & 1.019 & 982 & .934 & .984 & 976 & 1.001 & .972 & 1.001 & .994 & 942 & 1.008 & 1.001 & 1.005 \\
\hline \multirow{3}{*}{ Infosys } & Mean & 3.04 & 2.99 & 3.02 & 2.93 & 2.94 & 3.07 & 2.88 & 3.14 & 3.01 & 2.98 & 2.80 & 2.87 & 2.94 & 2.93 & 2.95 \\
\hline & $\mathrm{N}$ & 121 & 121 & 121 & 121 & 121 & 121 & 121 & 121 & 121 & 121 & 121 & 121 & 121 & 121 & 121 \\
\hline & $\begin{array}{l}\text { Std. } \\
\text { Deviation }\end{array}$ & 1.417 & 1.025 & 966 & .938 & .982 & 1.002 & 1.046 & 1.015 & .967 & 1.053 & 1.026 & 1.044 & 1.055 & 1.014 & .953 \\
\hline \multirow{3}{*}{ Accenture } & Mean & 3.05 & 2.91 & 2.83 & 2.98 & 2.96 & 2.96 & 2.94 & 2.84 & 2.82 & 3.01 & 3.15 & 3.03 & 3.14 & 2.93 & 2.93 \\
\hline & $\mathrm{N}$ & 114 & 114 & 114 & 114 & 114 & 114 & 114 & 114 & 114 & 114 & 114 & 114 & 114 & 114 & 114 \\
\hline & $\begin{array}{l}\text { Std. } \\
\text { Deviation }\end{array}$ & 1.408 & 1.113 & 964 & 1.076 & 1.043 & 1.051 & 1.020 & 1.006 & .985 & 1.005 & .967 & 1.004 & 1.008 & 1.122 & 1.007 \\
\hline \multirow{3}{*}{ HCL } & Mean & 3.05 & 3.08 & 3.00 & 3.10 & 3.00 & 3.00 & 3.12 & 3.07 & 2.98 & 2.92 & 3.10 & 3.07 & 2.75 & 3.15 & 2.83 \\
\hline & $\mathrm{N}$ & 59 & 59 & 59 & 59 & 59 & 59 & 59 & 59 & 59 & 59 & 59 & 59 & 59 & 59 & 59 \\
\hline & $\begin{array}{l}\text { Std. } \\
\text { Deviation }\end{array}$ & 1.432 & .980 & 975 & 1.037 & 1.106 & 1.151 & 1.122 & 1.007 & 1.098 & 1.125 & .952 & 937 & .950 & 1.087 & 1.045 \\
\hline
\end{tabular}

The company may reduce the attrition rate. Last but not the least HCL focuses mostly on, "Career development opportunities", this may be due to the fact that in contemporary competitive environment employees also look forward to strengthen their resume i.e. personal growth is an important factor for many of the employees, this could be the fact that HCL is focusing on employee development more than anything else. Further statistical significance of these difference of opinions is tested using analysis of variance, following table presents the results.

It can be observed from the analysis of variance table that only, "Workers participation in management activities" is non-significantly vary from company to company i.e. more or less 
all five companies follow this retention strategy with same intensity. Rest of all retention strategies vary from company to company significantly.

Table 6 Analysis of Variance for Retention Strategies

\begin{tabular}{|c|c|c|c|c|c|c|}
\hline & & Sum of Squares & Df & Mean Square & $\mathbf{F}$ & Sig. \\
\hline \multirow{3}{*}{ D. 1} & Between Groups & 47.790 & 4 & 11.948 & 6.030 & .000 \\
\hline & Within Groups & 13067.649 & 655 & 1.981 & & \\
\hline & Total & 13115.439 & 659 & & & \\
\hline \multirow{3}{*}{ D. 2} & Between Groups & 22.075 & 4 & 5.519 & 5.240 & .000 \\
\hline & Within Groups & 6946.046 & 655 & 1.053 & & \\
\hline & Total & 6968.121 & 659 & & & \\
\hline \multirow{3}{*}{ D. 3} & Between Groups & 36.053 & 4 & 9.013 & 9.016 & .000 \\
\hline & Within Groups & 6593.205 & 655 & 1.000 & & \\
\hline & Total & 6629.258 & 659 & & & \\
\hline \multirow{3}{*}{ D. 4} & Between Groups & 17.551 & 4 & 4.388 & 4.239 & .002 \\
\hline & Within Groups & 6826.934 & 655 & 1.035 & & \\
\hline & Total & 6844.485 & 659 & & & \\
\hline \multirow{3}{*}{ D.5 } & Between Groups & 2.838 & 4 & .710 & .700 & .592 \\
\hline & Within Groups & 6681.647 & 655 & 1.013 & & \\
\hline & Total & 6684.485 & 659 & & & \\
\hline \multirow{3}{*}{ D.6 } & Between Groups & 36.423 & 4 & 9.106 & 8.519 & .000 \\
\hline & Within Groups & 7049.198 & 655 & 1.069 & & \\
\hline & Total & 7085.621 & 659 & & & \\
\hline \multirow{3}{*}{ D.7 } & Between Groups & 33.660 & 4 & 8.415 & 8.146 & .000 \\
\hline & Within Groups & 6812.931 & 655 & 1.033 & & \\
\hline & Total & 6846.591 & 659 & & & \\
\hline \multirow{3}{*}{ D. 8} & Between Groups & 72.994 & 4 & 18.249 & 18.056 & .000 \\
\hline & Within Groups & 6665.490 & 655 & 1.011 & & \\
\hline & Total & 6738.485 & 659 & & & \\
\hline \multirow{3}{*}{ D.9 } & Between Groups & 28.797 & 4 & 7.199 & 7.085 & .000 \\
\hline & Within Groups & 6700.960 & 655 & 1.016 & & \\
\hline & Total & 6729.758 & 659 & & & \\
\hline \multirow{3}{*}{ D. 10} & Between Groups & 32.942 & 4 & 8.235 & 7.627 & .000 \\
\hline & Within Groups & 7120.680 & 655 & 1.080 & & \\
\hline & Total & 7153.621 & 659 & & & \\
\hline \multirow{3}{*}{ D.11 } & Between Groups & 114.600 & 4 & 28.650 & 29.258 & .000 \\
\hline & Within Groups & 6457.885 & 655 & .979 & & \\
\hline & Total & 6572.485 & 659 & & & \\
\hline \multirow{3}{*}{ D. 12} & Between Groups & 28.852 & 4 & 7.213 & 7.333 & .000 \\
\hline & Within Groups & \begin{tabular}{|l|l|}
6487.269 \\
\end{tabular} & 655 & .984 & & \\
\hline & Total & 6516.121 & 659 & & & \\
\hline \multirow{3}{*}{ D.13 } & Between Groups & \begin{tabular}{|l|}
73.419 \\
\end{tabular} & 4 & 18.355 & 18.245 & .000 \\
\hline & Within Groups & 6634.702 & 655 & 1.006 & & \\
\hline & Total & 6708.121 & 659 & & & \\
\hline \multirow{3}{*}{ D. 14} & Between Groups & 55.842 & 4 & 13.961 & 13.136 & .000 \\
\hline & Within Groups & 7009.249 & 655 & 1.063 & & \\
\hline & Total & 7065.091 & 659 & & & \\
\hline \multirow{3}{*}{ D. 15} & Between Groups & 29.957 & 4 & 7.489 & 7.130 & .000 \\
\hline & Within Groups & 6927.301 & 655 & 1.050 & & \\
\hline & Total & \begin{tabular}{|l|}
6957.258 \\
\end{tabular} & 659 & & & \\
\hline
\end{tabular}

Hence the null hypothesis is not rejected for D.5 (Workers participation in management activities) and it is rejected for rest of the statements (table -6). This shows that there is a statistically significant difference in agreement when it comes to workers participation in management activities. The highest agreement on the statement is observed in HCL with a mean score of 3 . 


\section{CONCLUSION}

In TCS the highest agreement appeared on the statements, "Rewards and Recognition given to deserving employees", this could be the prime strategy for TCS, it is also observed during the study that reward and recognition are major components in employee retention. On the other hand Wipro focuses most on, "Location transfer with promotion is given", this clearly shows that Wipro works on change of environment more rather than any other component. This may be due to the fact that stagnancy of work in IT sectors is debated over the period of time and change of environment and location may provide an employee breathe of freshness. In Infosys highest focus is on providing onsite opportunities and hence the highest agreement appeared on the statement, "Onsite opportunities are provided". This retention strategy can only work with the industry if it has enough options overseas. There is a charm amongst employees in working onsite and hence the retention strategies revolve around this in Infosys. Further in Accenture the highest agreement is observed on, "Good welfare measures are taken". It seems that the Accenture believed in providing welfare to employees and their Families. There are many companies that succeeded in high employee retention by focusing on employee welfare. This strategy provides employees a stress free environment. The HCL focuses mostly on, "Career development opportunities", this may be due to the fact that in contemporary competitive environment employees also look forward to strengthen their resume i.e. personal growth is an important factor for many of the employees. The results obtained in the paper are very useful for HR managers who are seeking a solution for reducing the rate of employee turnover and further the study can be carried out on the gap that are identified in this paper.

\section{REFERENCES}

[1] Alaydrus, M. Z. (2017). The Effect of Productive Zakah, Infaq and Shadaqah to the Growth of Micro-Enterprises and Welfare Mustahiq in Pasuruan. Journal of Islamic Economics Science, 1(1), 28-38.

[2] Banerjee, A. (2019). Failure of Employee Retention and Its Consequences on Organisation through Content Analysis. International Journal of Research-GRANTHAALAYAH, 7(3), 200207.

[3] Campion, M. A. (1991). Meaning and measurement of turnover: Comparison of alternative measures and recommendations for research. Journal of applied psychology, 76(2), 199.

[4] Chauhan, V. S., \& Patel, D. (2013). Employee turnover: A factorial study of IT industry. Journal of Strategic Human Resource Management, 2(1), 37.

[5] Cotton, J. L., \& Tuttle, J. M. (1986). Employee turnover: A meta-analysis and review with implications for research. Academy of management Review, 11(1), 55-70.

[6] Kashyap, V., \& Rangnekar, S. (2014). A structural equation model for measuring the impact of employee retention practices on employee's turnover intentions: An Indian perspective. South Asian Journal of Human Resources Management, 1(2), 221-247.

[7] March, J. S., \& Simon, H. A. (1958). HA (1958) Organizations. New York.

[8] Price, J. L. (1977). The study of turnover. Ames, Iowa. The Iowa State University Press. Prery, JL, and Rainey HG (1988), The Public-Private Distinction in Organization Theory: A Critique and Research Strategy, The Academy of Management Review, 13(2), 182-201.

[9] Satpal, Singh., \& Dhillon, M. (2019). Impact of Factors affecting Employee Retention on Turnover Intentions: In Indian IT Sector. International Journal on Emerging Technologies, 10 (4), 273-282.

[10] Sheridan, J. E. (1992). Organizational culture and employee retention. Academy of management Journal, 35(5), 1036-1056. 
[11] Singh, S., Singh, R., \& Dhillon, M. (2019). Impact of Retention Strategies in Indian IT Sector. Restaurant Business, 118(12), 539-559.

[12] Staw, B. M. (1980). The consequences of turnover. Journal of occupational Behaviour, 253273.

[13] Suhasini, N., \& Babu, T. N. (2013). Retention management: A strategic dimension of Indian it companies. International Journal of Management and Social Sciences Research, 2(2), 12-16.

[14] Woods, R. H. (1992). Managing hospitality human resources. Educational Institute of the American Hotel \& Motel Association. 